\title{
Studies of the transmissibility of the agent of bovine spongiform encephalopathy to the domestic chicken
}

\author{
Jo Moore ${ }^{1,3}$, Stephen AC Hawkins ${ }^{1}$, Anthony R Austin', Timm Konold', Robert B Green', lan W Blamire', \\ Ian Dexter', Michael J Stack', Melanie J Chaplin ${ }^{1}$, Jan PM Langeveld ${ }^{4}$, Marion M Simmons ${ }^{1 *}$, Yvonne I Spencer $^{1}$, \\ Paul R Webb ${ }^{1}$, Michael Dawson ${ }^{2}$ and Gerald AH Wells ${ }^{1}$
}

\begin{abstract}
Background: Transmission of the prion disease bovine spongiform encephalopathy (BSE) occurred accidentally to cattle and several other mammalian species via feed supplemented with meat and bone meal contaminated with infected bovine tissue. Prior to United Kingdom controls in 1996 on the feeding of mammalian meat and bone meal to farmed animals, the domestic chicken was potentially exposed to feed contaminated with the causal agent of BSE. Although confirmed prion diseases are unrecorded in avian species a study was undertaken to transmit BSE to the domestic chicken by parenteral and oral inoculations. Transmissibility was assessed by clinical monitoring, histopathological examinations, detection of a putative disease form of an avian prion protein (PrP) in recipient tissues and by mouse bioassay of tissues. Occurrence of a progressive neurological syndrome in the primary transmission study was investigated by sub-passage experiments.
\end{abstract}

Results: No clinical, pathological or bioassay evidence of transmission of BSE to the chicken was obtained in the primary or sub-passage experiments. Survival data showed no significant differences between control and treatment groups. Neurological signs observed, not previously described in the domestic chicken, were not associated with significant pathology. The diagnostic techniques applied failed to detect a disease associated form of PrP.

Conclusion: Important from a risk assessment perspective, the present study has established that the domestic chicken does not develop a prion disease after large parenteral exposures to the BSE agent or after oral exposures equivalent to previous exposures via commercial diets. Future investigations into the potential susceptibility of avian species to mammalian prion diseases require species-specific immunochemical techniques and more refined experimental models.

\section{Background}

The transmissible spongiform encephalopathies (TSE) or prion diseases are fatal neurodegenerative disorders characterised by vacuolation, neuronal loss, gliosis and accumulation of an abnormal form $\left(\mathrm{PrP}^{\mathrm{Sc}}\right)$ of a natural host encoded "prion" protein $\left(\operatorname{PrP}^{\mathrm{c}}\right)[1]$.

Naturally occurring TSE are reported exclusively in mammals. Among non-human species they include

\footnotetext{
* Correspondence: marion.simmons@ahvla.gsi.gov.uk

'Department of Pathology and Host Susceptibility, Animal Health and Veterinary Laboratories Agency, Woodham Lane, New Haw, Addlestone, Surrey KT15 3NB, UK

Full list of author information is available at the end of the article
}

scrapie in sheep and goats, chronic wasting disease in deer and elk, transmissible mink encephalopathy in farmed mink and bovine spongiform encephalopathy (BSE) in cattle and other species. BSE, initially diagnosed in Great Britain in domestic cattle [2]) and presenting as an extended common source epidemic, was shown to be transmitted via feeding commercial rations containing meat and bone meal (MBM) [3]. Unique among animal TSE, BSE was also transmitted via feed to several other captive bovid species [4] and through dietary inclusion of infected cattle tissues to a range of felids, both domestic [5] and zoo kept species [4]. Although the full extent of this species susceptibility to the BSE agent, 
which subsequently included humans [6], was not known in the early stages of the epidemic in cattle, the involvement of MBM as the primary vector of infection inevitably raised concerns regarding the potential infection of other domesticated livestock, including nonruminant species $[7,8]$. Ruminant-derived MBM was used as a component of domestic poultry rations until the United Kingdom ban on feeding mammalian MBM to all farm animals in April 1996 [9], providing oral exposure of this species to BSE infectivity at concentrations potentially similar to those promoting the bovine epidemic.

Neither at the time of the instigation of this study (June 1990) nor since, have there been published reports of naturally occurring avian TSE or successful transmission of a TSE to an avian species.

The present study examines the transmissibility of the BSE agent to domestic chickens by parenteral and oral routes of exposure. Transmission was initially evaluated on the basis of clinical monitoring of recipients for neurological disease, histopathological examinations for encephalopathic changes, and detection of aggregates of a proteinase $K(\mathrm{PK})$ resistant form of the putative disease form $\left(\mathrm{PrP}^{\mathrm{res}}\right)$ of an avian prion protein $\left(\operatorname{PrP}^{\mathrm{c}}\right)$ in brain tissue, equivalent to scrapie-associated fibril (SAF) extraction in the diagnosis of mammalian prion diseases. Immunohistochemistry (IHC) for the detection of a disease specific form of the prion protein $\left(\mathrm{PrP}^{\mathrm{d}}\right)$ without the use of proteases was also attempted on brain using mammalian derived antibodies to PrP. In view of the empirical nature of this approach further work was undertaken to identify mammalian PrP antibodies that were most likely to detect avian PrP. In addition, Western immunoblotting for the detection of $\mathrm{PrP}^{\text {res }}$ was undertaken similarly. Mouse bioassays for detection of tissue infectivity were also performed.

In the course of the primary transmission study a progressive neurological syndrome was observed in some male chickens of both parenteral and oral exposure groups without pathological evidence of a TSE. This syndrome was further investigated by sub-passage experiments.

\section{Methods}

All procedures were carried out in accordance with the Animal (Scientific Procedures) Act 1986, under Licence from the UK Government Home Office (Licence numbers: 70/3994, 70/5257).

\section{Inocula}

For the primary transmission study an inoculum was prepared as a $10 \% \mathrm{w} / \mathrm{v}$ homogenate, in saline, of pooled caudal medulla oblongata from two clinical BSE cases. These cases were confirmed by the statutory diagnostic methods in use at the time of their death in 1989: histopathological examination of the brain for spongiform encephalopathy and detection of SAF by negative-contrast transmission electron microscopy. Primary transmissions from brainstem of each of the donor cattle to inbred mice provided uniform disease characteristics consistent with the agent of BSE from previous sources (see cows 5 and 6 respectively from [10]). The uniformity of incubation periods obtained in the mice with those of the equivalent dilution of previously titrated inocula [11] suggested a titre for the present inoculum of $10^{5}$ intracerebral ID $_{50}$ mouse infectious units per gram.

For the sub-passage experiments in chickens three inocula were prepared, all comprising a $10 \% \mathrm{w} / \mathrm{v}$ homogenate of pooled brain and sciatic nerve in saline. One inoculum pool was derived from all parenterally exposed chickens which exhibited the progressive neurological syndrome, the second from orally exposed chickens which exhibited the syndrome, and the third from clinically normal, saline inoculated control chickens. The same inocula pools were used for the inoculation of mice.

\section{Animals and exposures}

Hybrid day old specific pathogen free (SPF) chicks were sourced for the study. For the primary transmission study 12 chicks were inoculated intracranially (i.c.) with $50 \mu \mathrm{l}$ of the homogenate at 1 day old and then intraperitoneally (i.p.) with $1 \mathrm{ml}$ at 2 weeks of age. To simulate the potential dietary exposure of domestic chicken to BSE contaminated feed, 11 chickens were inoculated with $5 \mathrm{~g}$ of pooled BSE affected brain tissue into the distal oesophagus/crop by gavage on 3 occasions, at 4, 5 and 6 weeks of age. This dose approximates to the average maximum daily intake of $\mathrm{MBM}$ at $15 \%$ incorporation into the diet for the first month of life. A further 14 chicks were inoculated i.c. with $50 \mu \mathrm{l}$ of a $10 \%$ saline solution at 1 day old, then i.p. with $1 \mathrm{ml}$ saline at 2 weeks of age and served as age matched controls for both the parenteral and oral primary exposure studies.

For the sub-passage experiments three groups of dayold SPF chicks were inoculated i.c. with $50 \mu \mathrm{l}$ of each test inoculum. Fifteen received inoculum derived from parenterally exposed chickens exhibiting the neurological syndrome; sixteen received inoculum from orally exposed chickens exhibiting the syndrome and 13 received inoculum from clinically normal, saline inoculated control chickens. Twelve chicks were inoculated i. c. with saline only.

All chicks used in the primary exposure study were housed initially in experimental groups arranged as separate cage racks, with each cage containing an entire group. As the chicks grew the number per cage was 
reduced until, at approximately 4 months of age, they were housed singly. Chickens used in the sub-passage study were housed in a free range floor system.

Prior to the enforcement of the ban on feeding mammalian MBM to all farmed animals and for the first 4.5 months of the primary exposure, chicks were reared on a commercial diet containing a premixed MBM component ( $0.4 \%$ by weight) some of which may, in retrospect, have contained ruminant-derived protein. Thereafter the commercial ration was replaced with a home-mixed, MBM free ration which was fed ad libitum. For the sub-passage experiment all chickens were reared and maintained on the same home-mixed ration, fed ad libitum.

All chickens were monitored clinically for up to 5 years post inoculation (p.i.) when they were killed and examined post-mortem. Chickens developing intercurrent disease were killed if welfare was compromised.

\section{Clinical monitoring}

The chickens were inspected daily for signs of abnormality by attendants at the time of husbandry duties, such as feeding and cleaning. In the primary study a veterinary clinician conducted a bi-weekly passive observation for 15 min per group. Any indications of abnormality were supported by an individual clinical examination that included testing of neurological reflexes and assessment of locomotion. These examinations were also conducted shortly before culling. Body weight, weekly food consumption and behaviour (time spent lying, standing, active, idle, preening or eating) were recorded. Weekly food consumption was recorded on four occasions. In the sub-passage study, the same methods were used but the passive clinical observations were conducted weekly.

Statistical analysis was performed using the Statistica package (version 10, Statsoft Ltd., Bedford, UK), which included analysis of variance of selected signs and survival analysis (chickens culled for welfare reasons were censored).

\section{Post-mortem sampling}

From all chickens in the primary exposure study the frontal cerebrum, sciatic nerve, skeletal muscles (pectoral and hindlimb adductors), liver, spleen, kidney, small intestine and bursa of Fabricius were aseptically sampled and stored frozen for possible subsequent bioassay studies. A segment of cervical spinal cord was taken for SAF extraction and stored at $-20^{\circ} \mathrm{C}$. The brain, spinal cord, sciatic nerve, pectoral and adductor muscles and bursa of Fabricius were also sampled for histopathological and immunohistochemical examinations. Additional tissues were sampled as gross post-mortem findings required, particularly where initial observations indicated changes potentially causal in intercurrent disease deaths. Central nervous system tissue was placed into $10 \%$ formol saline and other tissues were fixed in neutral buffered 10\% formalin. After post-mortem removal of the cervical spinal cord segment the remaining spinal cord was fixed in situ within the vertebral canal to avoid possible fresh dissection damage to the cord and was later removed for further sampling. Chickens which died or were killed because of intercurrent disease before the planned termination of the study were examined similarly.

From all chickens in the sub-passage study, selected fresh tissues were aseptically sampled post-mortem, including frontal cerebrum, cervical and thoracic spinal cord, sciatic nerve, pectoral muscle, adductor muscle, ischiotibial muscle, heart, liver, spleen, kidney, small intestine, and bursa of Fabricius. The range of tissues sampled for histopathological examination encompassed those for the primary exposure study. Chickens that died or were killed because of intercurrent disease before the planned kill date were examined similarly.

\section{Histopathology}

Blocks were prepared from coronal sections of the brain at eight levels, approximating to selected levels from an atlas of the chicken brain (levels 9,10,12,14,17,19, 23 and 24, see [12]) to achieve representation of all major brain regions. Transverse blocks of spinal cord (cervical, thoracic and lumbar) were also prepared. Sciatic nerve and skeletal muscles were blocked transversely and longitudinally. Visceral tissue samples were blocked routinely.

Tissues were fixed for 3-5 days and then processed overnight on an automatic tissue processor before embedding in paraffin wax. Sections $5 \mu \mathrm{m}$ thick were cut and stained by a modification of the routine haematoxylin and eosin method [13]. Muscles were stained using a collagen and elastin method.

\section{SAF examination}

Cervical spinal cord samples were prepared for SAF examination by an extraction technique as described previously $[14,15]$. The resulting negatively stained samples were examined in either a Phillips 410 or a CM10 transmission electron microscope at magnifications greater than 25,000. A positive result was recorded if one or more fibrils within the original definition [16] were identified. Where fibrils were not detected each sample was examined for 20 min before being declared negative. Thirty-three samples from the primary exposure study were examined: $10 / 12$ parenterally exposed chickens, $11 / 11$ orally exposed chickens, and $12 / 14$ control chickens. Thirty-six samples from the sub-passage study were examined similarly: 14/15 chickens inoculated with nervous tissue from parenterally exposed chickens in the primary exposure study, 10/16 chickens 
inoculated with nervous tissue from orally exposed chickens, and 12/13 chickens inoculated with nervous tissue from saline controls.

\section{Immunohistochemistry}

A series of IHC examinations were carried out on central nervous system tissues for the detection of a putative disease form of an avian prion protein. Interpretation of immunodetection was necessarily made without the benefit of an avian TSE/prion disease positive control. Controls included BSE affected bovine brainstem, BSE and scrapie affected sheep brainstem, omission of the primary antibody, substitution of the primary antibody with normal rabbit serum or immunoglobulin (Ig) $\mathrm{G}$ from the species in which each antibody was raised, and brainstem from normal cattle and sheep.

Initially, frontal cerebrum, cerebellum/medulla and spinal cord from one control (ID: 962) and one orally exposed (ID: 976) chicken from the primary exposure study were immunolabelled with antibodies IA8 and 971 F (Table 1). Subsequently, the same tissues from up to three chickens per treatment group (ID: 379, 390, 715, $853,866,928,929,946)$ in the sub-passage study were immunolabelled with antibodies 1B3, F99, IA8, L42, R145 and Rb486 (Table 1).

Investigations were also carried out which aimed to maximise the chances of detecting $\mathrm{PrP}^{\mathrm{d}}$. First, brain blocks from both the primary exposure and sub-passage studies were selected in which mild vacuolar changes had been detected. Secondly, since there are currently no commercially available antibodies raised against the chicken prion protein, epitope sequences for 24 ovine and bovine anti-PrP antibodies were aligned to the National Center for Biotechnology Information (NCBI) reference sequence for the chicken prion protein (NP_990796.1) to select potentially appropriate antibodies. Alignments were performed using the European Bioinformatics Institute European Molecular Biology
Open Software Suite (EBI EMBOSS) pairwise alignment algorithms [26] with a gap penalty of 25 to ensure fulllength matches. For each alignment the percent identity and percent similarity to the full-length of the epitope sequence was calculated. Two antibodies (R568 and 6 C2) were identified which had $100 \%$ identity to epitopes on the chicken prion protein. These antibodies were then used in further IHC examinations in parallel with antibodies R145, 2 G11 and P4.

Brain samples from six exposed chickens, which had displayed neurological signs and which had the longest survival times in their treatment group (ID: 388, 963, 972, 985, 977, 990) (Table 2), were selected for IHC examination. For two of the chickens (ID: 977, 990) for which both fixed and frozen brain was available, Western immunoblotting examinations were also conducted (see below). Brains samples from two healthy unexposed chickens were included as negative controls.

\section{Western immunoblotting (WB)}

For the detection of $\mathrm{PrP}^{\text {res }}$ by $\mathrm{WB}$ in brain tissue, from one orally exposed (ID: 977), one intracerebrally inoculated (ID: 990) (from the primary inoculation experiment) and two healthy non-exposed chickens, the commercially available BioRad TeSeE ${ }^{\mathrm{TM}}$ Western blot (BioRad, Marnes le Coquette, France) was used according to manufacturers instructions with a minor change. The test was modified by replacing the kit primary antibody with monoclonal antibody 6C2 [24]. No avian BSE-positive control tissue was available for profile comparison but two brain samples from healthy, non-inoculated chickens were included as negative controls.

\section{Mouse bioassays for detection of infectivity}

Three pooled inocula comprising brain and sciatic nerve from selected primary parenterally inoculated (ID: 980, 983, 984, 985), orally inoculated (ID: 965, 969, 976, 978) and saline inoculated control (ID: 952, 953, 957, 962)

Table 1 PrP antibodies used for immunohistochemistry

\begin{tabular}{|c|c|c|c|c|}
\hline Antibody & Mono/Polyclonal & Immunogen raised against & Dilution & Reference \\
\hline $1 \mathrm{~B} 3$ & Polyclonal & Mouse ME7 scrapie SAF & $1 / 1000$ & {$[17,18]$} \\
\hline IA8 & Polyclonal & Mouse ME7 scrapie SAF & $1 / 2500$ & {$[17]$} \\
\hline $971 \mathrm{~F}$ & Polyclonal & Bovine PrP 221-232 & $1 / 2500$ & {$[18]$} \\
\hline F99 & Monoclonal & Ovine PrP 220-225 & $1 / 4000$ and $1 / 8000$ & {$[19]$} \\
\hline $\mathrm{P} 4$ & Monoclonal & Ovine PrP 89-104 & $1 / 12000$ & [20] \\
\hline R145 & Monoclonal & Bovine PrP 221-232 & $1 / 100$ and $1 / 500$ & [21] \\
\hline$\llcorner 42$ & Monoclonal & Ovine PrP 145-163 & $1 / 250$ & [22] \\
\hline $\mathrm{Rb} 486$ & Polyclonal & Bovine PrP 240-254 & $1 / 2500$ & [22] \\
\hline R568 & Polyclonal & Ovine PrP 126-143 & $1 / 100$ & [23] \\
\hline $6 C 2$ & Monoclonal & Ovine PrP 114-120 & $1 / 100$ & [24] \\
\hline $2 \mathrm{G} 11$ & Monoclonal & Ovine PrP 146- $R^{154} R^{171}-182$ (recognising $R^{151}-R^{159}$ ) & $1 / 400$ & {$[25]$} \\
\hline
\end{tabular}


Table 2 Individual data for chickens in primary exposure study

\begin{tabular}{|c|c|c|c|c|c|}
\hline $\begin{array}{l}\text { Bird } \\
\text { Identification }\end{array}$ & Inoculum & $\begin{array}{l}\text { Route of } \\
\text { exposure }\end{array}$ & Sex & $\begin{array}{l}\text { Survival time } \\
\text { (days) }\end{array}$ & $\begin{array}{l}\text { Experimental outcome }(E / D)^{a} \text { and occurrence of syndromes } \\
(M / N)^{b}\end{array}$ \\
\hline 986 & Bovine BSE & Parenteral $^{c}$ & $f$ & 65 & (E) Neurological signs, NSL \\
\hline 988 & Bovine BSE & Parenteral & $f$ & 273 & (D)/NSL \\
\hline 982 & Bovine BSE & Parenteral & $\mathrm{m}$ & 274 & (D)/NSL \\
\hline 981 & Bovine BSE & Parenteral & $f$ & 378 & (E) Egg peritonitis \\
\hline $983^{d}$ & Bovine BSE & Parenteral & $m$ & 664 & (E) Acute onset (M) \\
\hline $980^{d}$ & Bovine BSE & Parenteral & $m$ & 1302 & (D)/NSL (M/N) \\
\hline $984^{d}$ & Bovine BSE & Parenteral & $m$ & 1486 & (D)/NSL (M) \\
\hline 989 & Bovine BSE & Parenteral & $f$ & 1780 & (D) Ovarian adenocarcinoma (N) \\
\hline 979 & Bovine BSE & Parenteral & $f$ & 1804 & (E) Ovarian adenocarcinoma (N) \\
\hline 987 & Bovine BSE & Parenteral & $f$ & 1841 & Terminal kill/NSL (M/N) \\
\hline $985^{\S}$ & Bovine BSE & Parenteral & $\mathrm{m}$ & 1841 & Terminal kill/NSL (M/N) \\
\hline 990 & Bovine BSE & Parenteral & $f$ & 1843 & Terminal kill/NSL (M/N) \\
\hline 966 & Bovine BSE & Oral & $f$ & 390 & (E) Hepatitis \\
\hline 970 & Bovine BSE & Oral & $f$ & 573 & (E) Weight loss \\
\hline $976^{d}$ & Bovine BSE & Oral & $m$ & 1230 & (E) (M) \\
\hline $978^{d}$ & Bovine BSE & Oral & $\mathrm{m}$ & 1413 & (E) (M) \\
\hline $969^{d}$ & Bovine BSE & Oral & $m$ & 1555 & (E) Collapse (M) \\
\hline $965^{d}$ & Bovine BSE & Oral & $m$ & 1601 & (E) (M) \\
\hline 967 & Bovine BSE & Oral & $f$ & 1808 & (D) Ovarian adenocarcinoma \\
\hline 971 & Bovine BSE & Oral & $f$ & 1830 & Terminal kill/NSL (N) \\
\hline 968 & Bovine BSE & Oral & $f$ & 1830 & Terminal kill/NSL (N) \\
\hline 977 & Bovine BSE & Oral & $m$ & 1834 & Terminal kill/NSL (M) \\
\hline 972 & Bovine BSE & Oral & $f$ & 1834 & Terminal kill/NSL (N) \\
\hline 959 & Saline & Parenteral & $f$ & 222 & (D) \\
\hline 958 & Saline & Parenteral & $\mathrm{m}$ & 395 & (E) Weight loss \\
\hline 955 & Saline & Parenteral & $m$ & 757 & (D) \\
\hline 960 & Saline & Parenteral & $\mathrm{m}$ & 862 & (E) Weight loss/NSL \\
\hline 956 & Saline & Parenteral & $\mathrm{m}$ & 1037 & (D)/NSL \\
\hline 964 & Saline & Parenteral & $\mathrm{m}$ & 1037 & (E) Neurological signs/NSL \\
\hline 951 & Saline & Parenteral & $m$ & 1225 & (E) Neurological signs/NSL \\
\hline 961 & Saline & Parenteral & $f$ & 1310 & (E) Egg peritonitis \\
\hline 954 & Saline & Parenteral & $f$ & 1528 & (E) Weight loss/NSL \\
\hline 963 & Saline & Parenteral & $f$ & 1547 & (D) Ovarian adenocarcinoma (N) \\
\hline $953^{b}$ & Saline & Parenteral & $\mathrm{m}$ & 1837 & (D) Meningoencephalitis (N) \\
\hline $952^{b}$ & Saline & Parenteral & f & 1868 & Terminal kill/NSL \\
\hline $962^{b}$ & Saline & Parenteral & $f$ & 1868 & Terminal kill/NSL (N) \\
\hline $957^{b}$ & Saline & Parenteral & $f$ & 1868 & Terminal kill/splenomegaly/meningo-encephalitis (N) \\
\hline
\end{tabular}

$m$ male; $f$ female

${ }^{\mathrm{a}} E$ euthanasia due to compromised welfare; $D$ found dead

${ }^{\mathrm{b}} M$ motor disturbance syndrome; $N$ narcolepsy

$c_{\text {intracranial and intraperitoneal }}$

NSL no significant lesions at necropsy

${ }^{\mathrm{d}}$ Donor chicken for sub-passage studies

chickens respectively (Table 2), were assayed in a panel of five inbred mouse strains (Rlll $\left(\mathrm{Sinc}^{\mathrm{s} 7}\right)$, C57BLJ6 $\left(\mathrm{Sinc}^{\mathrm{s}}{ }^{\mathrm{T}}\right), \mathrm{VM}\left(\mathrm{Sinc}^{\mathrm{p}}\right)$, IM $\left(\mathrm{Sinc}^{\mathrm{p}}{ }^{7}\right)$ and an F1 cross of C57BLJ6 and VM) according to standard procedures
[10]. Using 20 mice per strain group, each mouse was injected with $0.02 \mathrm{ml}$ i.c. and $0.1 \mathrm{ml}$ i.p. of a single inoculum. Mice were clinically monitored from 250 days p.i. and the clinical end-point, when the mice showed 
clear clinical signs of neurological disease, was determined according to established criteria for calculating incubation period [27]. End points for termination of assays were 900 days for the RIII, VM and IM mice, 950 days for C57BL mice, and 800 days for the F1 cross mice. Mice surviving to these end-points were killed and their brains removed and processed routinely for histopathological examination for evidence of a TSE-like encephalopathy and immunohistochemical examination for $\mathrm{PrP}^{\mathrm{d}}$ using rabbit antiserum $\mathrm{Rb} 486$ as described previously [28]. Mice which died or were killed because of intercurrent disease before the end point were examined similarly.

\section{Results}

Individual animal results of the primary and sub-passage transmission experiments are given in Tables 2 and 3 .

\section{Survival analysis}

Of the 93 chickens in the study 72 (77.42\%) were included in the Kaplan-Meier survival analysis while 21 $(22.58 \%)$ were censored. No significant difference was detected between treatment groups in the primary exposed $(P=0.34)$ (Figure 1$)$ or sub-passage $(P=0.79)$ (Figure 2) experiments. Overall, the survival times for the primary exposure and sub-passage groups were not significantly different $(P=0.74)$.

\section{Clinical assessments}

A number of chickens were lost to intercurrent diseases which included ovarian adenocarcinoma, sometimes with transcoelomic metastases and egg peritonitis in female chickens. Impaction of the crop also occurred. Degenerative joint disease featured in a proportion of long-surviving chickens. These disorders did not manifest with neurological signs and occurred in exposed and control chickens in both the primary and sub-passage experiments (Tables 2 and 3 ).

Body weight and behavioural observations were analysed using analysis of variance with treatment group and sex as factors. The males were found to be significantly heavier than the females $(P<0.05)$ but no significant differences between treatment groups were detected. On the last of the weekly occasions when food consumption was recorded, a highly significant $(P<$ 0.05 ) treatment effect was found. In this week the parentally and orally exposed chickens ate significantly less than the controls, $28 \%$ and $37 \%$ respectively. No significant treatment effects were found on the specific behavioural features recorded but it was apparent that males spent significantly more time idle compared with females.

Two clinical neurological syndromes were recognised in the primary experiments. First, a syndrome associated with feeding: chickens would appear to develop an episodic loss of consciousness resembling narcolepsy. This occurred in both exposed and control chickens. More female chickens displayed this behaviour than males (Table 4) and the episodes in females tended to be more pronounced than those displayed by male chickens.

The signs observed were evident during a period of feeding activity (sometimes this may have been simulated or "sham feeding") when affected chickens would appear to become semi-conscious, slowly adopting sternal and then lateral recumbency. They then remained still, apart from occasional weak wing or leg movements, for up to three minutes before suddenly and spontaneously regaining full consciousness. On recovery from an episode, affected chickens would often resume feeding immediately, a practice that then appeared to evoke repetition of the syndrome (see additional file 1: 979 NS, which shows one of these episodes during feeding).

Secondly, a motor disturbance syndrome (MDS) was observed in four parenterally exposed and four orally exposed male chickens. None of the female exposed or control chickens that survived to the terminal kill developed the syndrome (Table 4). The first case (ID: 983) presented at 1,302 days p.i. and others subsequent through to the terminal kill at 1,834 days p.i. In seven of the chickens the disorder was slowly progressive, while in one chicken there was an acute onset of clinical signs (ID: 983). Clinical signs associated with the disorder variably included: ataxia, deficits in righting reflexes, balance deficits, tremor, abduction of the leg to maintain standing posture, voice change, immobility, tendency to sternal and/or lateral recumbency, partial closing of the eyelids, and rapid dilatation and constriction of the pupil (see additional file 2: 980 MDS, which shows a chicken with balance deficits).

In the sub-passage experimental groups a number of chickens in all groups were lost to a similar range of intercurrent diseases as in the primary exposure experiment and these occurred to a similar extent in exposed and control chickens.

A number of chickens also developed a range of neurological signs including ventroflexion of the neck, abnormal head movements, ataxia, balance deficits, depressed mentation and weakness/collapse, resembling some aspects of the MDS, but the narcolepsy-like syndrome was not observed.

\section{Histopathology}

Overall, no significant or systematic degenerative pathology was identified in the brain, spinal cord, sciatic nerve or skeletal muscle tissues of any of the chickens. Relatively sparse multiple large vacuoles were observed in the superficial grey matter of the optic tectum, white matter tracts of the brainstem and cerebellar white 
Table 3 Individual data for recipient chickens in sub-passage study

\begin{tabular}{|c|c|c|c|c|}
\hline $\begin{array}{l}\text { Bird } \\
\text { identification }\end{array}$ & $\begin{array}{l}\text { Primary exposure group source of } \\
\text { inoculum }\end{array}$ & Sex & $\begin{array}{l}\text { Survival time } \\
\text { (days) }\end{array}$ & Experimental outcome $(E / D)^{b}$ \\
\hline 387 & Parenteral BSE & $m$ & 111 & (E) Pecking trauma \\
\hline 391 & Parenteral BSE & $f$ & 131 & (E) Neurological signs/NSL \\
\hline 392 & Parenteral BSE & $f$ & 353 & (E) Prolapsed oviduct \\
\hline 385 & Parenteral BSE & $m$ & 916 & (E) Neurological signs/NSL \\
\hline 384 & Parenteral BSE & $m$ & 1059 & (D) Pneumonia \\
\hline 390 & Parenteral BSE & $f$ & 1217 & (E) Ovarian adenocarcinoma \\
\hline 393 & Parenteral BSE & $f$ & 1229 & (E) Ovarian adenocarcinoma \\
\hline 395 & Parenteral BSE & $f$ & 1266 & (E) Ovarian adenocarcinoma \\
\hline 379 & Parenteral BSE & $m$ & 1377 & (E) Neurological signs/NSL \\
\hline 394 & Parenteral BSE & $f$ & 1728 & (D) Ovarian adenocarcinoma \\
\hline 389 & Parenteral BSE & $f$ & 1728 & (E) Ovarian adenocarcinoma \\
\hline 376 & Parenteral BSE & $m$ & 1834 & Terminal kill/NSL \\
\hline 378 & Parenteral BSE & $m$ & 1834 & Terminal kill/NSL \\
\hline 382 & Parenteral BSE & $m$ & 1834 & Terminal kill/NSL \\
\hline 388 & Parenteral BSE & $m$ & 1834 & Terminal kill/NSL \\
\hline 945 & Oral BSE & $f$ & 154 & (E) Pecking injuries \\
\hline 943 & Oral BSE & $f$ & 209 & (E) Pecking injuries \\
\hline 930 & Oral BSE & $m$ & 353 & (E) Crop impaction \\
\hline$\overline{931}$ & Oral BSE & $m$ & 353 & (E) Crop impaction \\
\hline 942 & Oral BSE & $f$ & 448 & (E) Egg peritonitis \\
\hline 928 & Oral BSE & $m$ & 891 & (E) Musculoskeletal/neurological signs \\
\hline 935 & Oral BSE & $f$ & 940 & (E) Wing fracture \\
\hline 937 & Oral BSE & f & 951 & (E) Musculoskeletal/neurological signs \\
\hline 929 & Oral BSE & $m$ & 967 & (E) Neurological signs \\
\hline 927 & Oral BSE & $m$ & 1258 & (D) Previous neurological signs. \\
\hline 946 & Oral BSE & $f$ & 1483 & (E) Egg peritonitis \\
\hline 939 & Oral BSE & $f$ & 1636 & (D) Ovarian adenocarcinoma \\
\hline 933 & Oral BSE & $m$ & 1833 & Terminal kill/degenerative joint disease \\
\hline 941 & Oral BSE & $\mathrm{m}$ & 1833 & Terminal kill/degenerative joint disease \\
\hline$\overline{936}$ & Oral BSE & $f$ & 1833 & Terminal kill/mild egg peritonitis \\
\hline 926 & Oral BSE & $m$ & 1833 & Terminal kill/degenerative joint disease \\
\hline 870 & Parenteral saline control & $f$ & 156 & (E) Prolapsed oviduct \\
\hline 860 & Parenteral saline control & $f$ & 209 & (E) Pecking trauma \\
\hline 865 & Parenteral saline control & m & 328 & (E) Crop impaction \\
\hline 858 & Parenteral saline control & $\mathrm{m}$ & 513 & (E) Suppurative keratitis \\
\hline 862 & Parenteral saline control & $m$ & 1206 & (D) Possible ataxia/NSL \\
\hline 853 & Parenteral saline control & $m$ & 1219 & (E) Neurological signs/NSL \\
\hline 866 & Parenteral saline control & $m$ & 1343 & (E) Musculoskeletal/neurological signs/NSL \\
\hline 856 & Parenteral saline control & $f$ & 1372 & (E) Neurological signs/NSL \\
\hline 851 & Parenteral saline control & $\mathrm{m}$ & 1620 & (D) Possible neurological signs/NSL \\
\hline 855 & Parenteral saline control & $m$ & 1643 & (D) Musculoskeletal/neurological signs/NSL \\
\hline 863 & Parenteral saline control & $m$ & 1655 & $\begin{array}{l}\text { (E) Musculoskeletal/neurological signs/degenerative joint } \\
\text { disease }\end{array}$ \\
\hline 871 & Parenteral saline control & $f$ & 1666 & (D) Ovarian adenocarcinoma \\
\hline 867 & Parenteral saline control & f & 1835 & Terminal kill/degenerative joint disease \\
\hline 710 & Saline $e^{a}$ & $m$ & 351 & (E) Musculoskeletal/neurological signs. \\
\hline
\end{tabular}


Table 3 Individual data for recipient chickens in sub-passage study (Continued)

\begin{tabular}{lllll}
\hline 704 & Saline $^{a}$ & f & 446 & (E) Prolapsed oviduct \\
\hline 712 & Saline $^{a}$ & m & 730 & (E) Intermittent haemorrhage from comb \\
\hline 708 & Saline $^{a}$ & f & 761 & (E) Coelomic mass \\
\hline 715 & Saline $^{a}$ & m & 968 & (E) Neurological signs \\
\hline 707 & Saline $^{a}$ & f & 1439 & (D)Ovarian adenocarcinoma \\
\hline 706 & Saline $^{a}$ & f & 1448 & (E) Ovarian adenocarcinoma \\
\hline 705 & Saline $^{a}$ & f & 1721 & (E) Egg peritonitis \\
\hline 714 & Saline $^{a}$ & m & 1729 & Terminal kill/multifocal non-suppurative \\
\hline 709 & Saline $^{a}$ & & & meningoencephalitis \\
\hline 711 & Saline $^{a}$ & m & 1729 & Terminal kill/NSL \\
\hline 713 & Saline $^{a}$ & $m$ & 1730 & Terminal kill/NSL \\
\hline Al & & & & Terminal kill/NSL
\end{tabular}

All recipient chickens were exposed intracranially

aSaline controls, not derived from primary transmission groups

$m$ male; $f$ female

${ }^{\mathrm{b}} E$ euthanasia due to compromised welfare; $D$ found dead

NSL no significant lesions at necropsy

matter of both control and exposed chickens. Vacuolar change was also often seen in the spinal cord grey matter but occurred in both control and exposed chickens.

\section{SAF examination}

No TSE associated fibrils could be detected in any of the spinal cords from inoculated or control chickens from which material was examined.

\section{Immunohistochemistry}

Each antibody tested showed patterns of particulate or diffuse immunolabelling, but similar patterns and intensities of labelling for individual antibodies occurred in both control and BSE exposed chickens. For example, R486 immunolabelled multi-focal neuropil areas in the spinal central grey matter, R586 showed diffuse high background immunolabelling with intense labeling of

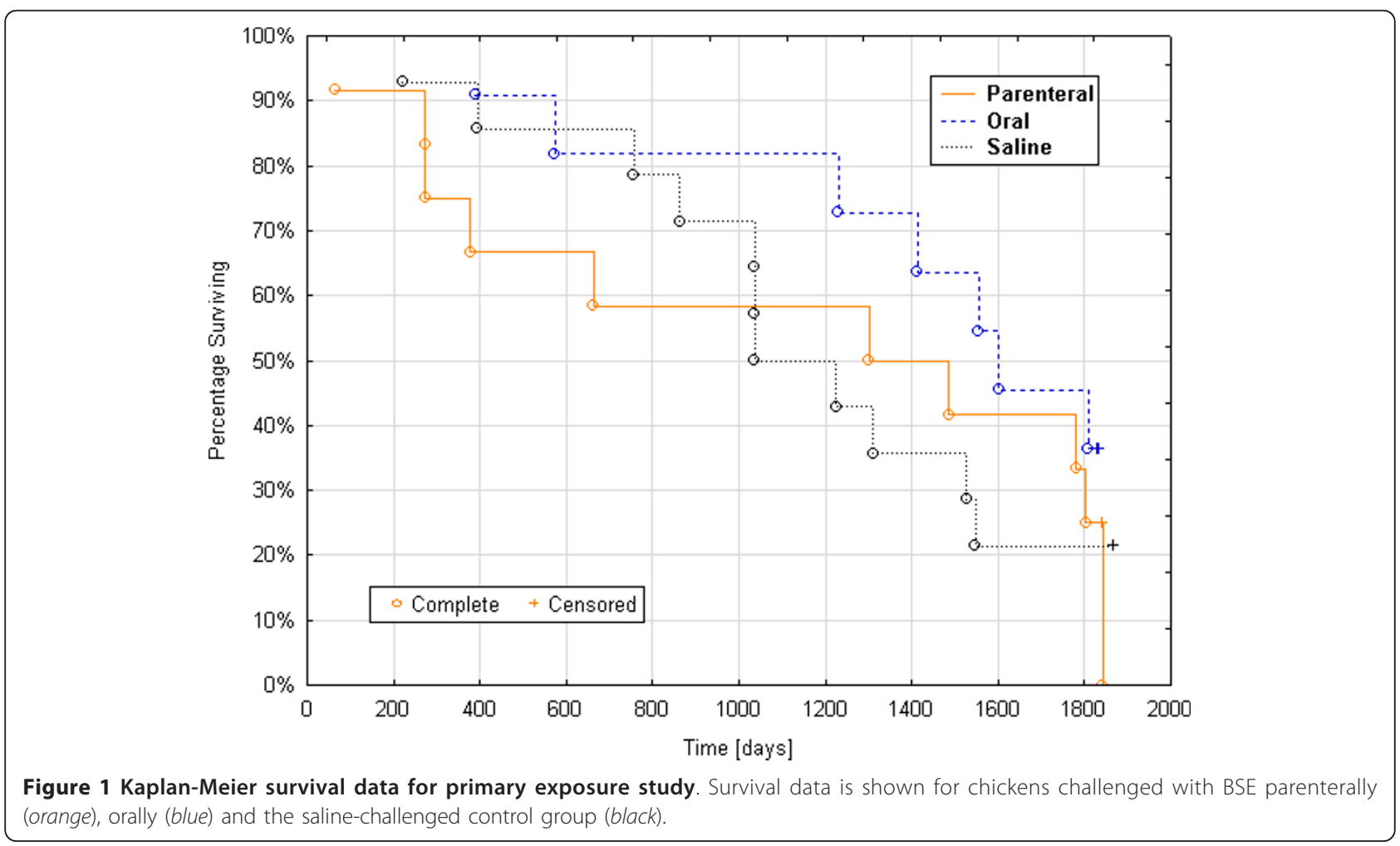




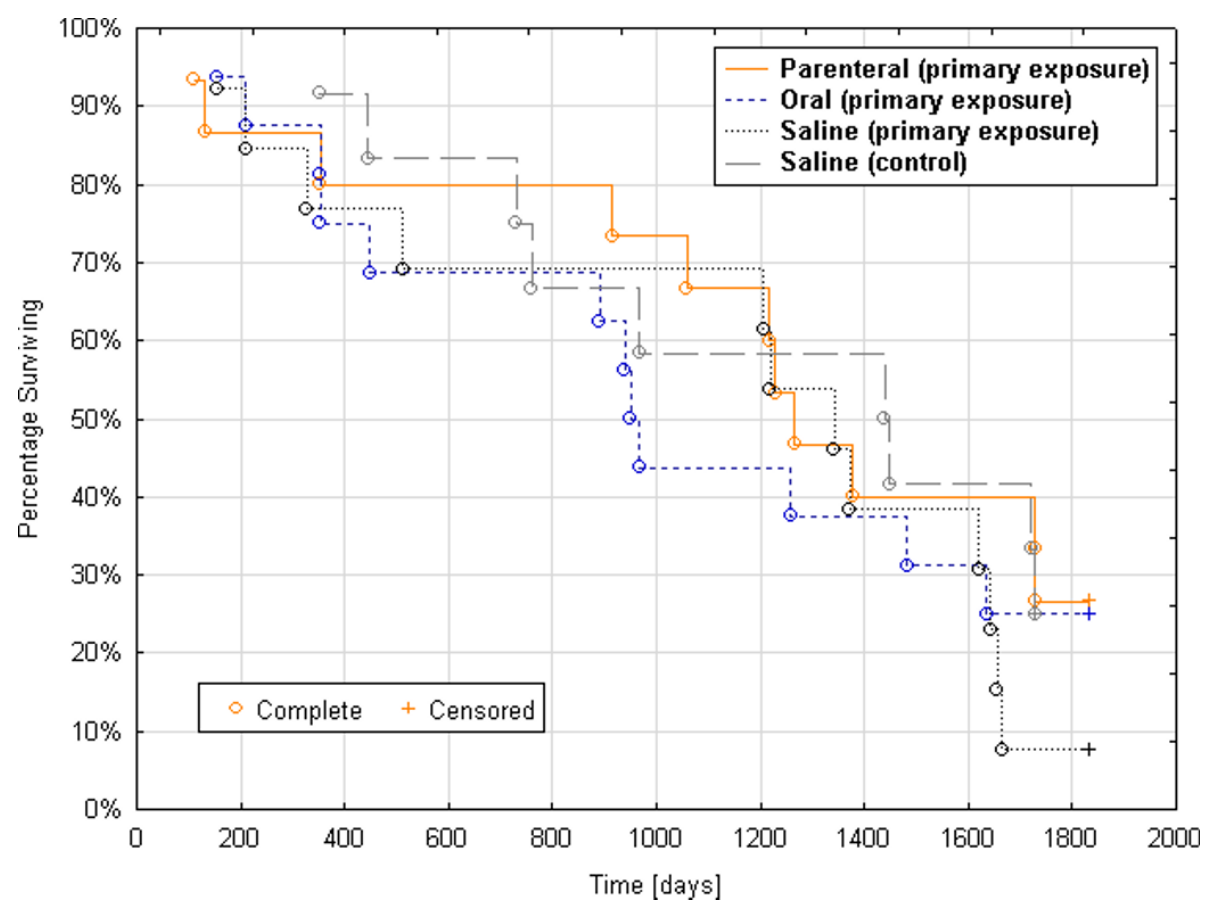

Figure 2 Kaplan-Meier survival data for sub-passage study. Survival data is shown for chickens challenged intracranially with inoculum made from parenterally (orange), orally (blue) BSE-challenged chickens exhibiting the neurological syndrome, from clinically normal salinechallenged control chickens (black) of the primary exposure study and a separate intracranially saline-challenged control group (grey).

neuronal perikarya and neuropil of some strata. With other antibodies including R145 the predominant labelling was a widespread fine particulate form. Similar labelling was observed with antibody $6 \mathrm{C} 2$ and remained in tissue sections where the primary antibody $(6 \mathrm{C} 2)$ was omitted or replaced with mouse IgG.

IA8 also immunolabelled the spinal dorsal horn grey matter and spinal ganglia perikarya and IB3 and L42 immunolabelled populations of neurons.

\section{Western immunoblotting}

Protein bands were detected by $\mathrm{mAb} 6 \mathrm{C} 2$ in the non-PK treated chicken samples as well as the known positive bovine BSE and ovine scrapie control samples, however

Table 4 Incidence of cases of feeding-associated narcolepsy and motor disturbance syndrome (MDS) by sex

\begin{tabular}{lllll}
\hline & \multicolumn{2}{l}{ Narcolepsy $^{\mathbf{a}}$} & \multicolumn{2}{l}{ MDS $^{\mathbf{a}}$} \\
\hline Treatment group & $\mathbf{m}$ & $\mathbf{f}$ & $\mathbf{m}$ & $\mathbf{f}$ \\
\hline Parenterally exposed & $2 / 3$ & $4 / 4$ & $4 / 4$ & $0 / 4$ \\
\hline Orally exposed & $0 / 1$ & $3 / 3$ & $5 / 5$ & $0 / 4$ \\
\hline Control & $1 / 1$ & $5 / 6$ & $0 / 5$ & $0 / 6$ \\
\hline
\end{tabular}

$m$ male; $f$ female

${ }^{a}$ Number of chickens affected/number of chickens surviving at the time of onset of the syndrome the molecular mass of the bands detected in the chicken samples was too great to be compatible with the sequence-based estimate for chicken PrP. Following PK digestion, $\operatorname{PrP}^{\text {res }}$ was only detected in the positive BSE and scrapie control samples and not in samples from inoculated or non-inoculated chickens.

\section{Mouse bioassay}

There was no confirmatory evidence of infectivity in any of the pools. A number of mouse brains showed vacuolar changes, e.g. in the corpus callosum, which are commonly seen in aged wild-type mice [29].

\section{Discussion}

No evidence of the susceptibility of chickens to BSE emerged from these primary inoculation or sub-passage experiments. Kaplan-Meier survival data showed no significant differences between control and treatment groups. No pathology, which in mammals would have significance in relation to TSE, was identified in any of the chickens. Although there have been no substantiated reports of naturally occurring avian prion disease, Schoon et al. [30] described three cases of interest in red-necked ostriches (Struthio camelus) in two zoos in northern Germany, in 1986, 1988 and 1989. These birds, and two subsequent cases in 1992-1993, displayed progressive clinical signs of a nervous disorder with 
ataxia, changes to balance, uncoordinated movements during feeding and had vacuolar changes in the brainstem, but transmission studies failed to establish the nature of the disorder [31].

The two clinically defined syndromes observed in the present study appear to be more of interest in terms of the husbandry and experimental circumstances than of significance to the study aims.

The narcolepsy-like behaviour seemed to be associated with the approach of food satiety, but the behaviour was not observed in the sub-passage study when the housing was a free range floor system, suggesting that prolonged cage confinement in the primary study may have played a role.

Although in the primary study the MDS was observed only in exposed chickens, insufficient male control chickens survived to the terminal kill to determine whether there was a statistically significant correlation between exposure to BSE and the development of MDS, or whether MDS was a disorder peculiar to the males of the strain of chicken used in the experiment.

Similar signs to those of the MDS observed in the primary exposure study also occurred in each group in the sub-passage study, but the more frequent occurrence of such cases in the chickens that received tissues from the saline control chickens of the primary study than recipients of tissues from BSE exposed chickens, argues strongly against any relationship to exposure to the BSE agent.

Neither the feeding associated narcolepsy nor MDS have previously been reported in commercially farmed domestic chickens. However, these syndromes were observed in circumstances that were themselves unusual. The lifespan of commercially farmed chickens is usually approximately 45 days (broiler chickens) to 18 months (laying chickens) and their behaviour is not scrutinized in detail. Since neither of the syndromes or any other intercurrent diseases were observed in chickens less than 2 years of age it is possible that the observed behavioural abnormalities could be inherent to this strain of chickens without having been reported previously.

No lesions were observed in the central or peripheral nervous system that were significant either in terms of transmission of BSE or the clinical neurological signs observed. The vacuolation observed in the central nervous system of both the chickens and mice is most probably age and or host strain related.

Using biochemical extraction and PK digestion techniques, identical or similar to the one used in this study, SAF have been detected in a wide range of prion diseases, both natural and experimental [2,5,16,32-41]. SAF are considered to be aggregates of the abnormal prion protein and, prior to the routine introduction of immunochemical methods for the detection of the protein, were the most studied pathological marker for the TSE [42]. The detection of SAF in the diagnosis of mammalian TSE has been shown to be a relatively insensitive approach but unlike immunochemical methods, provides morphologic detection of the extracted altered protein, independent of the problems of specificity of immunochemical detection in a species for which reagents and appropriate control materials are lacking. Therefore, not withstanding sensitivity issues, negative results by this method in the present study might be considered to give more definitive information on the absence of significant accumulations of an altered form of the prion protein in central nervous tissue.

No disease-specific immunolabelling was seen with any of the antibodies used, including $6 \mathrm{C} 2$ and R568. The widespread punctate immunolabelling observed appear related to technical factors which are largely irresolvable in the absence of species and disease specific antibodies, positive control material and appropriately developed epitope demasking procedures.

In the present study mammalian derived PrP antibodies were not able to detect abnormal forms of PrP in the neural tissues of the chicken. Even if it were assumed that there was successful uptake of infectivity into nervous tissues there are a number of possible reasons for the failure of the mammalian abnormal prion protein to initiate a disease process.

The three-dimensional structures of mammalian and chicken $\operatorname{PrP}^{\mathrm{c}}$ are quite similar although there is only $\sim 30 \%$ sequence identity [43-45]. The C-terminal domain of mammalian $\operatorname{PrP}^{\mathrm{c}}$ forms a globular domain with a unique fold which consists of three $\alpha$-helices and a short, anti-parallel $\beta$-sheet. Chicken $\operatorname{PrP}^{\mathrm{c}}$ has a number of additional structural elements not found in mammalian $\operatorname{PrP}^{\mathrm{c}}$ : a $3_{10}$ helix between helices 2 and 3, an insertion between helices 2 and 3 which forms a flexibly disordered loop containing a glycosylation site and elongation of the $\mathrm{N}$-terminal end of helix 3 [43]. The mechanism of conversion of $\operatorname{PrP}^{\mathrm{c}}$ to $\operatorname{PrP}^{\mathrm{Sc}}$ is not known but it is likely that it involves close range interactions between the two molecules. The additional structural elements present in chicken $\operatorname{PrP}^{\mathrm{Sc}}$ may inhibit or prevent this interaction. For example, changing the charge distribution at the protein's surface as occurs in the Gly200Lys mutation associated with familial CreutzfeldtJakob disease [46], which slows or prevents the propagation of $\operatorname{Pr} \mathrm{P}^{\mathrm{d}}$.

The key difference between the structures of the $\operatorname{PrP}^{\mathrm{c}}$ and $\operatorname{PrP}^{\mathrm{Sc}}$ isoforms is the relative proportions of $\alpha$ helices and $\beta$-sheets (reviewed in [47]). Dima and Thirumali [48] showed that the amino acid sequence of helix 2 of chicken $\operatorname{PrP}^{\mathrm{c}}$ has a higher propensity to form $\alpha$ helices than the same region of mammalian (mouse) 
$\operatorname{PrP}^{\mathrm{c}}$. This suggests that for chicken $\operatorname{PrP}^{\mathrm{c}}$ the transition from $\alpha$-helix to $\beta$-sheet may not occur as readily as it does in mammals, or may not occur at all. Therefore, even if bovine $\mathrm{PrP}^{\mathrm{Sc}}$ was able to engage in close range interactions with chicken $\operatorname{PrP}^{\mathrm{C}}$, it may not be able to induce the structural transformation which is necessary for formation of chicken $\operatorname{PrP}^{\mathrm{Sc}}$.

Even assuming successful conversion of chicken $\operatorname{PrP}^{\mathrm{c}}$ into $\mathrm{PrP}^{\mathrm{Sc}}$ there is evidence that it lacks key metal-binding sites which may render it weakly- or non-pathogenic [49]. In mammalian $\operatorname{PrP}^{\mathrm{c}}$ there is a high-affinity copperbinding site located around His96 [50-53]. This site was found to be highly conserved in mammals but absent in the non-mammalian species examined, including chicken [49]. When copper or other divalent cations are absent or present at very low levels mammalian $\operatorname{PrP}^{\mathrm{c}}$ becomes more susceptible to proteolytic degradation and conversion efficiency is reduced (reviewed in [54]). If the affinity of chicken $\operatorname{PrP}^{\mathrm{C}}$ for copper is lower than in mammals it follows that chicken $\mathrm{PrP}^{\mathrm{Sc}}$ would be more susceptible to proteolytic degradation.

Although in the present study the experimental models used involved same species sub-passage and wild type mouse tissue assay after primary exposure to the BSE agent, it is possible that the chicken, or other avian species, are susceptible to other TSE agents after parenteral exposure. In a study where chickens were intravenously inoculated with a TME agent passaged in mink [55] putatively small amounts of infectivity were recovered by mink bioassay from chicken lymphoreticular tissues sampled at 30 and 148 days p.i. but the chickens did not show any neurological signs or pathological changes in the brain. No other diagnostic studies of the chickens' tissues were performed. It is unclear whether this observation was related to uptake and persistence of inoculum, or replication of agent in the tissues.

\section{Conclusion}

The present study addressed only the potential for the development of disease in the domestic chicken due to the BSE agent after parenteral or per os administration. Questions as to the possibilities of the uptake of inoculum into cells and whether infection can occur with a resultant sub-clinical state from exposure to TSE agents requires different approaches and highly sensitive species-specific immunochemical techniques, although the negative results of sub-passage experiments conducted in this study do not suggest establishment or persistence of infectivity in the donor tissues. The sequence of avian PrP is highly conserved among the avian species which have been tested and which are used for food, including pigeon [56], duck [57], quail [56] and peacock [57]. It is therefore unlikely that BSE could be successfully transmitted to these species.

\section{Additional material}

Additional file 1: Female chicken, number 979, at 1270 days post parenteral inoculation (primary exposure study). It is first seen

feeding from a trough (time 8:40 is displayed in the left bottom corner of the clip). It then retreats with its eyes closed and appears to sleep, sitting down with its head resting on the side of the trough. At 8:44, it wakes up, moves its head and gets up before feeding again from the trough.

Additional file 2: Female chicken, number 980, at 1256 days post parenteral inoculation (primary exposure study). This chicken has difficulty maintaining balance as can be seen when it is pushed to the side or encouraged to move. It is generally reluctant to walk and has a tendency to stand with flexed intertarsal joints. By comparison, chicken 989, which was at the same time point post inoculation when filmed and is shown in the overlaid video clip, walks without difficulty and stands upright.

\section{Acknowledgements}

The authors thank the many past and present colleagues in the Departments of Animal Services, Pathology, Virology and Molecular Pathogenesis and Genetics and the Centre for Epidemiology and Risk Analysis, Veterinary Laboratories Agency Weybridge, UK, who, over the protracted period of the studies, have provided much professional and technical assistance. Dr Richard Kimberlin is also gratefully acknowledged for the considerable advice and encouragement given in the planning and design of the studies. The work was funded by the former Ministry of Agriculture, Fisheries and Food, UK (Projects SE1805 and SE1806) and latterly by the Food Standards Agency, UK (Projects M03002 and M03003).

\section{Author details}

'Department of Pathology and Host Susceptibility, Animal Health and Veterinary Laboratories Agency, Woodham Lane, New Haw, Addlestone, Surrey KT15 3NB, UK. ${ }^{2}$ Centre for Epidemiology and Risk Analysis, Animal Health and Veterinary Laboratories Agency, Woodham Lane, New Haw, Addlestone, Surrey KT15 3NB, UK. ${ }^{3}$ School of Veterinary and Biomedical Sciences, Murdoch University, South Street, Murdoch, WA 6150, Australia. ${ }^{4}$ Central Veterinary Institute of Wageningen UR (CVI), P.O. Box 65, 8200, AB Lelystad, Netherlands.

\section{Authors' contributions}

JM performed the IHC and part drafted the manuscript; SACH led the project latterly; ARA and TK undertook all clinical assessments and contributed to the manuscript; RBG and ID performed the bioassays; IB performed the bioassays and the chicken post mortem examinations; MJS and MJC performed the SAF examinations, interpreted the Western immunoblotting and contributed to the manuscript; JPML performed the epitope sequence matching and provided MAbs 6C2 and R568; MMS contributed to the IHC and the manuscript; YIS and PRW developed and applied the IHC method; MD was involved with initial project design and initiation, and contributed to the manuscript; GAHW led the project initially, conducted histopathological examinations and part drafted the manuscript.

\section{Competing interests}

The authors declare that they have no competing interests.

Received: 13 September 2011 Accepted: 17 November 2011 Published: 17 November 2011

\section{References}

1. Hörnlimann B, Riesner D, Kretzschmar H: Prions in humans and animals Berlin: de Gruyter; 2007.

2. Wells GA, Scott AC, Johnson CT, Gunning RF, Hancock RD, Jeffrey M, Dawson M, Bradley R: A novel progressive spongiform encephalopathy in cattle. Vet Rec 1987, 121:419-420.

3. Wilesmith JW: Bovine spongiform encephalopathy. Vet Rec 1988, 122:614. 
4. Kirkwood JK, Cunningham AA: Portrait of prion diseases in zoo animals. In Prions in humans and animals. Edited by: Hörnlimann B, Riesner D, Kretzschmar H. Berlin: de Gruyter; 2007:250-256.

5. Pearson GR, Wyatt JM, Gruffyddjones TJ, Hope J, Chong A, Higgins RJ, Scott AC, Wells GAH: Feline Spongiform Encephalopathy - Fibril and PrP Studies. Vet Rec 1992, 131:307-310.

6. Will RG, Ironside JW, Zeidler M, Cousens SN, Estibeiro K, Alperovitch A Poser S, Pocchiari M, Hofman A, Smith PG: A new variant of CreutzfeldtJakob disease in the UK. Lancet 1996, 347:921-925.

7. Lamming E: Report of the Expert Group on Animal Feedingstuffs: recommendations and government's response London: Ministry of Agriculture, Fisheries and Food (MAFF); 1992.

8. Matthews D, Cooke BC: The potential for transmissible spongiform encephalopathies in non-ruminant livestock and fish. Rev Sci Tech 2003, 22:283-296.

9. Order: The Bovine Spongiform Encephalopathy (Amendment) Order 1996. HMSO. London; 1996, No. 962.

10. Bruce M, Chree A, McConnell I, Foster J, Pearson G, Fraser H: Transmission of bovine spongiform encephalopathy and scrapie to mice: strain variation and the species barrier. Philos Trans R Soc Lond B Biol Sci 1994, 343:405-411

11. Fraser H, Bruce ME, Chree A, McConnell I, Wells GAH: Transmission of bovine spongiform encephalopathy and scrapie to mice. J Gen Virol 1992, 73:1891-1897.

12. Yoshikawa T: Atlas of the brains of domestic animals Tokyo: University of Tokyo Press; 1968.

13. Wells GAH, Hancock RD, Cooley WA, Richards MS, Higgins RJ, David GP: Bovine spongiform encephalopathy: Diagnostic significance of vacuolar changes in selected nuclei of the medulla oblongata. Vet Rec 1989, 125:521-524.

14. Scott AC, Wells GAH, Chaplin MJ, Dawson M: Bovine spongiform encephalopathy: detection of fibrils in the central nervous system is not affected by autolysis. Res Vet Sci 1992, 52:332-336.

15. Stack MJ, Scott AC, Done SH, Dawson M: Scrapie associated fibril detection on decomposed and fixed ovine brain material. Res Vet SCi 1993, 55:173-178.

16. Merz PA, Somerville RA, Wisniewski HM, lqbal K: Abnormal fibrils from scrapie-infected brain. Acta Neuropathol 1981, 54:63-74.

17. Farquhar CF, Somerville RA, Ritchie LA: Post-mortem immunodiagnosis of scrapie and bovine spongiform encephalopathy. J Virol Methods 1989, 24:215-221.

18. Wells GA, Wilesmith JW: The neuropathology and epidemiology of bovine spongiform encephalopathy. Brain Pathol 1995, 5:91-103.

19. O'Rourke Kl, Baszler TV, Besser TE, Miller JM, Cutlip RC, Wells GAH, Ryder SJ, Parish SM, Hamir AN, Cockett NE, Jenny A, Knowles DP: Preclinical diagnosis of scrapie by immunohistochemistry of third eyelid lymphoid tissue. J Clin Microbiol 2000, 38:3254-3259.

20. Hardt M, Baron T, Groschup MH: A comparative study of immunohistochemical methods for detecting abnormal prion protein with monoclonal and polyclonal antibodies. J Comp Pathol 2000, 122:43-53.

21. Terry LA, Marsh S, Ryder SJ, Hawkins SAC, Wells GAH, Spencer YI: Detection of disease-specific PrP in the distal ileum of cattle exposed orally to the agent of bovine spongiform encephalopathy. Vet Rec 2003, 152:387-392.

22. Cooley WA, Clark JK, Ryder SJ, Davis LA, Farrelly SSJ, Stack MJ: Evaluation of a rapid western immunoblotting procedure for the diagnosis of bovine spongiform encephalopathy (BSE) in the UK. J Comp Pathol 2001, 125:64-70.

23. van Keulen LJ, Schreuder BE, Meloen RH, Mooij-Harkes G, Vromans ME, Langeveld JP: Immunohistochemical detection of prion protein in lymphoid tissues of sheep with natural scrapie. J Clin Microbiol 1996, 34:1228-1231.

24. Rigter A, Langeveld JP, Timmers-Parohi D, Jacobs JG, Moonen PL, Bossers A: Mapping of possible prion protein self-interaction domains using peptide arrays. BMC Biochem 2007, 8:6.

25. Andréoletti O, Berthon P, Marc D, Sarradin P, Grosclaude J, van Keulen L, Schelcher F, Elsen JM, Lantier F: Early accumulation of $\operatorname{PrP}(\mathrm{Sc})$ in gutassociated lymphoid and nervous tissues of susceptible sheep from a Romanov flock with natural scrapie. J Gen Virol 2000, 81:3115-3126.

26. Rice P, Longden I, Bleasby A: EMBOSS: the European Molecular Biology Open Software Suite. Trends Genet 2000, 16:276-277.
27. Dickinson AG, Meikle VM, Fraser H: Identification of a gene which controls the incubation period of some strains of scrapie agent in mice. J Comp Pathol 1968, 78:293-299.

28. Green R, Horrocks C, Wilkinson A, Hawkins SAC, Ryder SJ: Primary isolation of the bovine spongiform encephalopathy agent in mice: agent definition based on a review of 150 transmissions. J Comp Pathol 2005, 132:117-131.

29. Fraser $H$, McBride PA: Parallels and contrasts between scrapie and dementia of the Alzheimer type and ageing: strategies and problems for experiments involving life span studies. In Senile dementia of the Alzheimer type: early diagnosis, neuropathology and animal models. Edited by: Traber J, Gispen WH. Berlin: Springer Verlag; 1985:250-268.

30. Schoon HA, Brunckhorst D, Pohlenz J: [Spongiform encephalopathy in a red-necked ostrich (Struthio camelus)]. Tierarztl Prax 1991, 19:263-265.

31. Wells GAH, Pohlenz J, Hawkins SAC, Matthews D: Portrait of a spongiform encephalopathy in birds and the transmissibility of mammalian prion diseases to birds. In Prions in humans and animals. Edited by: Hörnlimann B, Riesner D, Kretzschmar H. Berlin: de Gruyter; 2007:279-283.

32. Scott AC, Done SH, Venables C, Dawson M: Detection of scrapieassociated fibrils as an aid to the diagnosis of natural sheep scrapie. Vet $\operatorname{Rec} 1987,120: 280-281$

33. Rubenstein R, Merz PA, Kascsak RJ, Carp Rl, Scalici CL, Fama CL, Wisniewski HM: Detection of scrapie-associated fibrils (SAF) and SAF proteins from scrapie-affected sheep. J Infect Dis 1987, 156:36-42.

34. Peet RL, Curran JM: Spongiform encephalopathy in an imported cheetah (Acinonyx jubatus). Aust Vet J 1992, 69:171.

35. Merz PA, Somerville RA, Wisniewski HM, Manuelidis L, Manuelidis EE: Scrapie-associated fibrils in Creutzfeldt-Jakob disease. Nature 1983, 306:474-476.

36. Merz PA, Rohwer RG, Kascsak R, Wisniewski HM, Somerville RA, Gibbs CJ, Gajdusek DC: Infection-specific particle from the unconventional slow virus diseases. Science 1984, 225:437-440.

37. Kirkwood JK, Wells GA, Cunningham AA, Jackson SI, Scott AC, Dawson M, Wilesmith JW: Scrapie-like encephalopathy in a greater kudu (Tragelaphus strepsiceros) which had not been fed ruminant-derived protein. Vet Rec 1992, 130:365-367.

38. Hamir AN, Miller JM, O'Rourke Kl, Bartz JC, Stack MJ, Chaplin MJ: Transmission of transmissible mink encephalopathy to raccoons (Procyon lotor) by intracerebral inoculation. J Vet Diagn Invest 2004, 16:57-63.

39. Hamir AN, Miller JM, Cutlip RC, Kunkle RA, Jenny AL, Stack MJ, Chaplin MJ Richt JA: Transmission of sheep scrapie to elk (Cervus elaphus nelsoni) by intracerebral inoculation: final outcome of the experiment. J Vet Diagn Invest 2004, 16:316-321.

40. Guiroy DC, Williams ES, Song KJ, Yanagihara R, Gajdusek DC: Fibrils in brain of Rocky Mountain elk with chronic wasting disease contain scrapie amyloid. Acta Neuropathol 1993, 86:77-80.

41. Gibson PH, Somerville RA, Fraser H, Foster JD, Kimberlin RH: Scrapie associated fibrils in the diagnosis of scrapie in sheep. Vet Rec 1987, 120:125-127.

42. Prusiner SB: Novel proteinaceous infectious particles cause scrapie. Science 1982, 216:136-144.

43. Calzolai L, Lysek DA, Pérez DR, Güntert P, Wüthrich K: Prion protein NMR structures of chickens, turtles, and frogs. Proc Natl Acad Sci USA 2005, 102:651-655

44. Wopfner F, Weidenhöfer G, Schneider R, von Brunn A, Gilch S, Schwarz TF, Werner T, Schätzl HM: Analysis of 27 mammalian and 9 avian PrPs reveals high conservation of flexible regions of the prion protein. $J \mathrm{Mo} /$ Biol 1999, 289:1163-1178.

45. Gabriel JM, Oesch B, Kretzschmar H, Scott M, Prusiner SB: Molecular cloning of a candidate chicken prion protein. Proc Natl Acad Sci USA 1992, 89:9097-9101.

46. Zhang Y, Swietnicki W, Zagorski MG, Surewicz WK, Sönnichsen FD: Solution structure of the E200K variant of human prion protein. Implications for the mechanism of pathogenesis in familial prion diseases. $J$ Biol Chem 2000, 275:33650-33654

47. Riesner D: The scrapie isoform of the prion protein $\mathrm{PrP}^{\mathrm{Sc}}$ compared to the cellular isoform PrP ${ }^{C}$. In Prions in humans and animals. Edited by: Hörnlimann B, Riesner D, Kretzschmar H. Berlin: de Gruyter; 2007:104-118. 
48. Dima Rl, Thirumalai $D$ : Exploring the propensities of helices in $\operatorname{Pr} P(C)$ to form beta sheet using NMR structures and sequence alignments. Biophys J 2002, 83:1268-1280.

49. Ji HF, Zhang HY, Chen LL: Why are prion diseases precluded by nonmammals? Trends Biochem Sci 2007, 32:206-208.

50. Burns CS, Aronoff-Spencer E, Legname G, Prusiner SB, Antholine WE, Gerfen GJ, Peisach J, Millhauser GL: Copper coordination in the full-length, recombinant prion protein. Biochemistry 2003, 42:6794-6803.

51. Gaggelli E, Bernardi F, Molteni E, Pogni R, Valensin D, Valensin G, Remelli M, Luczkowski M, Kozlowski H: Interaction of the human prion PrP(106-126) sequence with copper(II), manganese(II), and zinc(11): NMR and EPR studies. J Am Chem Soc 2005, 127:996.

52. Jackson GS, Murray I, Hosszu LL, Gibbs N, Waltho JP, Clarke AR, Collinge J: Location and properties of metal-binding sites on the human prion protein. Proc Natl Acad Sci USA 2001, 98:8531-8535.

53. Jobling MF, Huang X, Stewart LR, Barnham KJ, Curtain C, Volitakis I, Perugini M, White AR, Cherny RA, Masters CL, Barrow CJ, Collins SJ, Bush Al, Cappai R: Copper and zinc binding modulates the aggregation and neurotoxic properties of the prion peptide PrP106-126. Biochemistry 2001, 40:8073-8084.

54. Barnham KJ, Cappai R, Beyreuther K, Masters CL, Hill AF: Delineating common molecular mechanisms in Alzheimer's and prion diseases. Trends Biochem Sci 2006, 31:465-472.

55. Marsh RF, Burger D, Eckroade R, Zu Rhein GM, Hanson RP: A preliminary report on the experimental host range of the transmissible mink encephalopathy agent. J Infect Dis 1969, 120:713-719.

56. Zhang L, Li N, Wang QG, Fan BL, Meng QY, Wu CX: Cloning and sequencing of quail and pigeon prion genes. Anim Biotechnol 2002, 13:159-162.

57. Yang JM, Zhao DM, Liu HX, Li N, Hao YX, Ning ZY, Qin XH: Comparative analysis of the prion protein open reading frame nucleotide sequences in peacock and parakeet. Virus Genes 2005, 30:193-196.

doi:10.1186/1756-0500-4-501

Cite this article as: Moore et al: Studies of the transmissibility of the agent of bovine spongiform encephalopathy to the domestic chicken. BMC Research Notes 2011 4:501.

\section{Submit your next manuscript to BioMed Central and take full advantage of:}

- Convenient online submission

- Thorough peer review

- No space constraints or color figure charges

- Immediate publication on acceptance

- Inclusion in PubMed, CAS, Scopus and Google Scholar

- Research which is freely available for redistribution

Submit your manuscript at www.biomedcentral.com/submit 